\title{
Lack of Associations of Ten Candidate Coronary Heart Disease Risk Genetic Variants and Subclinical Atherosclerosis in Four U.S. Populations: the Population Architecture using Genomics and Epidemiology (PAGE) Study
}

\author{
Lili Zhang ${ }^{a}$, Nora Franceschini ${ }^{b}$, Petra Buzkovac ${ }^{c}$ Christina L. Wassel ${ }^{d}$, Mary J. Roman ${ }^{d}$, \\ Kari E. North ${ }^{\mathrm{b}}$, Dana C. Crawford ${ }^{\mathrm{e}}$, Jonathan Boston ${ }^{\mathrm{e}}$, Kristin D. Brown-Gentry ${ }^{\mathrm{e}}$, Shelley A. \\ Cole $^{f}$, Ewa Deelman ${ }^{g}$, Robert Goodloe ${ }^{e}$, Gerardo Heiss ${ }^{b}$, Nancy S. Jenny ${ }^{h}$, Neal W. \\ Jorgensen $^{c}$, Tara C. Matise ${ }^{i}$, Bob E. McClellan Jr. ${ }^{e}$, Alejandro Q. Nato Jr.', Marylyn D. \\ Ritchie $^{\mathrm{e}}$, Sarah Wilson ${ }^{\mathrm{e}}$, and WH Linda Kao ${ }^{\mathrm{a},{ }^{*}}$ \\ aDepartment of Epidemiology, Johns Hopkins Bloomberg School of Public Health, Baltimore, \\ Maryland, USA \\ bDepartment of Epidemiology, University of North Carolina, Chapel Hill, North Carolina, USA \\ 'Department of Biostatistics, University of Washington, Seattle, Washington, USA \\ dDivision of Cardiology, Weill Cornell Medical College, New York, New York, USA \\ e'Center for Human Genetics Research, Department of Molecular Physiology and Biophysics, \\ Vanderbilt University, Nashville, Tennessee, USA \\ fTexas Biomedical Research Institute, San Antonio, Texas, USA \\ IInformation Sciences Institute, University of Southern California, Los Angeles, California, USA \\ hDepartment of Pathology, University of Vermont College of Medicine, Burlington, Vermont, USA \\ iDepartment of Genetics, Rutgers University, Piscataway, New Jersey, USA
}

\section{Abstract}

Background-A number of genetic variants have been discovered by recent genome-wide association studies for their associations with clinical coronary heart disease (CHD). However, it is unclear whether these variants are also associated with the development of CHD as measured by subclinical atherosclerosis phenotypes, ankle brachial index (ABI), carotid artery intima-media thickness (cIMT) and carotid plaque.

\begin{abstract}
Methods-Ten CHD risk single nucleotide polymorphisms (SNPs) were genotyped in individuals of European American (EA), African American (AA), American Indian (AI), and Mexican American (MA) ancestry in the Population Architecture using Genomics and Epidemiology (PAGE) study. In each individual study, we performed linear or logistic regression
\end{abstract}

(C) 2013 Elsevier Ireland Ltd. All rights reserved.

*Corresponding Author: Dr. W.H. Linda Kao, PhD, MHS, Department of Epidemiology, Johns Hopkins Bloomberg School of Public Health, 615 N. Wolfe St., Room W6513, Baltimore, MD, USA, 21205. Tel.: +1 410614 0945; fax: +1 410955 0863; wkao@jhsph.edu.

Publisher's Disclaimer: This is a PDF file of an unedited manuscript that has been accepted for publication. As a service to our customers we are providing this early version of the manuscript. The manuscript will undergo copyediting, typesetting, and review of the resulting proof before it is published in its final citable form. Please note that during the production process errors may be discovered which could affect the content, and all legal disclaimers that apply to the journal pertain. 
to examine population-specific associations between SNPs and ABI, common and internal cIMT, and plaque. The results from individual studies were meta-analyzed using a fixed effect inverse variance weighted model.

Results-None of the ten SNPs was significantly associated with ABI and common or internal cIMT, after Bonferroni correction. In the sample of 13,337 EA, 3,809 AA, and 5,353 AI individuals with carotid plaque measurement, the GCKR SNP rs780094 was significantly associated with the presence of plaque in $\mathrm{AI}$ only $(\mathrm{OR}=1.32,95 \%$ confidence interval: $1.17,1.49$, $\left.P=1.08 \times 10^{-5}\right)$, but not in the other populations $(P=0.90$ in EA and $P=0.99$ in AA). A 9 p21 region SNP, rs 1333049, was nominally associated with plaque in EA $(\mathrm{OR}=1.07, P=0.02)$ and in $\mathrm{AI}(\mathrm{OR}=1.10, \mathrm{P}=0.05)$.

Conclusions-We identified a significant association between rs780094 and plaque in AI populations, which needs to be replicated in future studies. There was little evidence that the index CHD risk variants identified through genome-wide association studies in EA influence the development of CHD through subclinical atherosclerosis as assessed by cIMT and ABI across ancestries.

\section{Keywords}

ankle brachial index; carotid artery intima-media thickness; carotid plaque; coronary heart disease; genetic association study; multiethnic populations; subclinical atherosclerosis

\section{Introduction}

Coronary heart disease (CHD) is the leading cause of death and a major health burden worldwide ${ }^{1}$. Subclinical atherosclerosis phenotypes, including carotid artery intima-media thickness (cIMT), carotid plaque, and resting ankle-brachial index (ABI), reflect the degree of atherosclerosis in coronary arteries and peripheral arteries. The associations between cIMT and plaque and the subsequent development of incident CHD, ischemic stroke, and heart failure have been well established in multiple epidemiologic studies ${ }^{2-8}$. ABI is an assessment of the patency of the lower extremity arteries as an indication of the presence of peripheral artery disease, and has also been associated with multiple clinical cardiovascular outcomes $^{9-11}$.

Recent genome-wide association studies (GWAS), mostly conducted in populations of European ancestry, have identified a number of single nucleotide polymorphisms (SNPs) associated with $\mathrm{CHD}^{12-18}$. Particularly, SNPs in the chromosome 9p21 region (e.g. rs 1333049) have been consistently associated with clinical CHD and related conditions in multiple studies ${ }^{12-18}$. However, in many cases, the biologic mechanisms underlying these associations remain unknown. Determination of whether these variants are associated with intermediate cardiovascular phenotypes, such as subclinical atherosclerosis, may help further our understanding of pathogenic mechanisms for CHD. To date, there have been six GWAS of subclinical atherosclerosis in $\mathrm{EA}^{18-23}$. Two studies identified several genomewide significant loci for common cIMT and plaque which have not been associated with CHD previously ${ }^{20}$. A GWAS study of ABI identified associations with rs10757269, a SNP in high LD with rs1333049 $\left(\mathrm{r}^{2}>0.8\right)$ at the $9 \mathrm{p} 21$ region. ${ }^{21}$

Several other smaller studies that have examined the associations between CHD risk SNPs and subclinical atherosclerosis have shown mixed results. ${ }^{22-26}$. Two candidate gene studies in European descent individuals reported associations of rs1333049 with prevalent $(P=$ 0.004 to 0.006 in different samples $)$ and incident $(\mathrm{P}<0.0001)$ carotid plaque ${ }^{24}$, and $\mathrm{ABI}(P$ $\left.=1.3 \times 10^{-4}\right)^{25}$. However, other studies in European populations (sample sizes ranging from 854 to 2277) showed a lack of association between CHD risk SNPs and common cIMT $^{26-28}$. 
Overall, most studies were conducted in populations of European descent, had relatively small sample sizes, and not always analyzed carotid artery plaque burden. Therefore, we conducted the current study, as a part of the Population Architecture using Genomics and Epidemiology (PAGE) Study ${ }^{29}$, to investigate whether genetic variants reported to be associated with CHD in individuals of European ancestry are associated with ABI, common and internal cIMT, and carotid artery plaque in individuals of European American (EA), as well as African American (AA), American Indian (AI) and Mexican American (MA).

\section{Methods and Materials}

\section{Study population}

Data from five population-based studies in the PAGE study were included: the Atherosclerosis Risk In Communities (ARIC) Study ${ }^{30}$, the Cardiovascular Health Study $(\mathrm{CHS})^{31}$, the Strong Heart Study (SHS) ${ }^{32}$, the Strong Heart Family Study (SHFS) ${ }^{33}$, and the National Health and Nutrition Examination Surveys (NHANES 1999-2002), the latter of which is accessed by Epidemiologic Architecture for Genes Linked to Environment (EAGLE) investigators ${ }^{34}$. Study designs of these five studies are summarized in Supplemental Table 1. Participants in all five studies provided written informed consents. All studies were approved by the institutional review boards of the participating institutions.

Participants were excluded if they did not self-identify themselves as one of the following four populations: EA, AA, AI, or MA, or if they did not consent to genetic research. Participants without genotype information or missing information on phenotypes were further excluded from analyses. Participants with $\mathrm{ABI}>1.4$ were excluded from the analyses of ABI. Total sample sizes for analyses of ABI were 15,113 in EA, 4,472 in AA, 1,984 in AI and 944 in MA. The sample sizes for analyses of cIMT were 13,002 in EA, 3,615 in AA and 5,315 in AI. The sample sizes for analyses of plaque were 13,330 in EA, 3,807 in AA and 5,318 in AI.

\section{SNP genotyping}

Using GWAS results that were published as of January 2009, we selected the following ten candidate SNPs: rs2144300 (GALNT2) ${ }^{16}$, rs599839 (CELSR2/PSRC1/SORT1) ${ }^{14}$, rs780094 $(G C K R)^{16}, \mathrm{rs} 499818(6 \mathrm{p} 24.1)^{18}, \mathrm{rs} 10757278(9 \mathrm{p} 21)^{13}, \mathrm{rs} 1333049(9 \mathrm{p} 21)^{12},{ }^{14}, \mathrm{rs} 2383206$ $(9 \mathrm{p} 21)^{17}, \mathrm{rs} 2383207(9 \mathrm{p} 21)^{13}, \mathrm{rs} 17228212(S M A D 3)^{14}$, and rs2549513 $(16 \mathrm{q} 23.1)^{18}$.

For the majority of the SNPs, the CALiCo Core Genotyping Laboratory at Human Genetics Center at University of Texas (Houston, TX) genotyped samples from ARIC, CHS, SHS and SHFS using Taqman assays (Applied Biosystems by Life Technology, Carlsbad, CA). For some of the SNPs in both the ARIC study and the CHS, GWAS data (Affymetrix 6.0 for ARIC and Illumina Human 370CNV BeadChip for CHS) ${ }^{35}$ were used: rs2549513 in ARIC and rs2383207, rs2549513, rs780094 and rs499818 in CHS were genotyped in their respective GWAS arrays. In addition, rs2383207 and rs499818 in ARIC were derived from imputation of the GWAS panel with around 2.5 million SNPs using the phase II HapMap European CEU reference panel. In EAGLE, NHANES 1999-2002 genotyping was performed by the Vanderbilt University DNA Resources Core using the Life Technologies OpenArray (rs599839) and the Illumina BeadXpress (rs2383206 and rs17228212). Genotyping in EAGLE was also performed in the laboratory of Dr. Jonathan Haines for rs2144300, rs780094, rs10757278, and rs2383207 using the PLEX $^{\circledR}$ Gold assay (Sequenom ${ }^{\circledR}$, Inc, San Diego, CA). Quality control assessments included sample call rates (> 90\%), concordance of blinded replicates (> 98\%) and deviation from Hardy-Weinberg equilibrium among controls within self-reported racial groups $(P \geq 0.01)$, except for rs 10757278 in ARIC AA (excess in heterozygotes, $P=0.001$ ). For imputed SNPs, the 
posterior probability of the most likely genotype $\left(\mathrm{r}^{2}\right)$ was 0.97 for rs 2383207 and 0.91 for rs499818.

Outcome measurement-Outcomes were taken from Visit 1 of the ARIC study (198789), Year 5 of the CHS (1994-95), Phase III of the SHS (1998-99), Phase IV of the SHFS (2001-03) and NHANES 1999-2002. All studies defined ABI as the ratio of the mean systolic blood pressure of both ankles to the brachial systolic blood pressure of the right arm, except for the ARIC study, where the systolic blood pressure from one randomly selected ankle was used. In NHANES, only adults aged 40 years and older at the study interview were measured for ABI.

In all studies except for NHANES, cIMT and plaque were measured by trained and certified sonographers using standardized protocols and equipment. In NHANES, cIMT and plaque were not measured. The study protocols and descriptive and quality control statistics have been previously published ${ }^{36-40}$. All studies used high-resolution B-mode real-time ultrasound to bilaterally assess the presence of discrete plaque and cIMT in the common, bifurcation and internal carotid artery except for the SHS and the SHFS, where internal cIMT was not measured. At each arterial segment, multiple measurements of the far wall of the cIMT were taken, and the derived mean cIMT of multiple measurements of left and right sides was used in the current analysis. Each study considered the presence of plaques differently when measuring cIMT. In the ARIC study, cIMT was measured regardless of the presence of plaque. In the CHS, cIMT measurement was centered at the site of plaque. In the SHS and the SHFS, cIMT was never obtained at the level of a discrete plaque. Each study also defined carotid plaque differently. In the SHS and the SHFS, plaque was defined as focal thickening of $>50 \%$ of the surrounding wall at any available arterial segments. In the ARIC study, plaque was defined if two of the following three criteria were met: 1) abnormal arterial wall thickness (defined as cIMT $>1.5 \mathrm{~mm}$ ); 2) abnormal shape (protrusion into the lumen, loss of alignment with adjacent arterial wall boundary); 3) abnormal wall texture (brighter echoes than adjacent boundaries). In the CHS, plaque was defined as stenosis degree less than $25 \%$ because most plaques are non-obstructive ${ }^{36,40,41}$. All phenotypes were carefully harmonized across studies for the purpose of meta-analysis ${ }^{29}$.

\section{Statistical Methods}

All study-specific association analyses were stratified by self-reported race/ethnicity (EA, AA, AI and MA). Natural log transformation of cIMT measurements was performed. An additive genetic model was assumed for all SNPs. The associations between SNPs and ABI, common cIMT and internal cIMT were examined using multivariate linear regression adjusting for sex, age (at baseline), and center if applicable. Logistic regression was used for the analyses of plaque adjusting for sex, age (at baseline), and center if applicable. In the SHFS, a variance components-based biometrical model with random effects was used to account for kinship ${ }^{42}$. The population-specific beta coefficients or log odds ratios (ORs) were meta-analyzed across studies using a fixed effect inverse variance weighted model to obtain joint estimates. To reduce type I error in results of associations, the Bonferroni correction was applied (alpha $=0.05 / 10=0.005$ ).

Exploratory analyses were performed to examine potential effect modification by CHD risk factors (e.g. type 2 diabetes, hypertension). In each study, we stratified the populationspecific samples into subgroups (type 2 diabetes: yes/no; hypertension: yes/no) and further evaluated the heterogeneity of associations of SNPs with outcomes of interest between subgroups. We used Cochran's $Q$ test to assess heterogeneity across studies and across subgroups $^{43}$. A $Q$ statistic with $P$ for heterogeneity $\left(P_{\text {het }}\right)<0.05$ indicated significant heterogeneity. 
Besides the simple model with adjustment of sex, age and center (if applicable), two sets of sensitivity analyses were performed: 1) in all five studies, a complex model was performed adjusting for sex, age, center if applicable, body mass index (BMI), smoking (current/ former/never smoker), hypertension, type 2 diabetes, low density lipoprotein (LDL) cholesterol, high density lipoprotein (HDL) cholesterol and triglyceride levels. All covariates were from the visit when the outcomes were derived; 2) to examine the potential confounding effect of population stratification, in the ARIC study, we adjusted for principal components (PCs) that were derived from GWAS data ${ }^{44}$ and were associated with the outcomes at alpha $=0.05$. In the SHFS, to test for population stratification, we compared the likelihood of a model in which the association parameters, $\beta b$ (between family genotype score) and $\beta \mathrm{w}$ (within family genotype score), were estimated, to the likelihood of a model in which they were constrained to be equal, as would be the case in the absence of population stratification ${ }^{45,46}$. Analyses were performed with either Stata 11 (College Station, Texas) or SAS V9.2 (Cary, NC) in all studies except SHFS. Analyses in the SHFS were implemented in the SOLAR (Sequential Oligogenic Linkage Analysis Routines, San Antonio, Texas) software package (version 4.4) ${ }^{46}, 47$. Meta-analyses were conducted using "metan" module in Stata 11. Aggregate statistics related to this work will be available via $\mathrm{dbGaP}$ as part of the PAGE study.

We performed power calculations assuming an additive genetic effect, risk allele frequencies of the target populations, a two-sided alpha $=0.005$, using continuous phenotype distributions or population baseline prevalence from the target populations (Quanto V. 1.2.4 $)^{48}$.

\section{Results}

Baseline characteristics of the study participants by population are summarized in Table 1 . The average ABIs in EA, AA, AI, and MA were 1.11, 1.09, 1.12 and 1.11, respectively. In the analyses of cIMT and plaque, because of the inclusion of the SHFS, the AI study population was larger $(\mathrm{n}=5,353)$ and younger (mean age $=50.8$ years) compared to the samples used for the ABI analyses ( $\mathrm{n}=1,984$, mean age $=63.3$ years). The mean of common cIMT was very similar in the EA $(0.77 \mathrm{~mm})$ and AA $(0.78 \mathrm{~mm})$ populations, both of which were higher than the mean of common cIMT in AI $(0.70 \mathrm{~mm})$. On the other hand, the prevalence of plaque was much higher in $\mathrm{AI}(45.0 \%)$, compared to $32.9 \%$ in EA and $31.6 \%$ in AA.

Associations between each of the ten SNPs and subclinical atherosclerosis phenotypes from the simple model are presented in Figure 1 and Tables $2-5$. In meta-analyses, there was no evidence for heterogeneity of associations across studies $\left(P_{\text {het }}>0.05\right.$, Tables 2-5). For ABI, common and internal cIMT, there was no significant association of any of the ten SNPs at the 0.005 level. However, there was a significant association between rs780094 (minor allele frequency $=0.20$ ) and the presence of plaque in the AI population (age-, sex-adjusted OR = $1.32,95 \%$ confidence interval $(\mathrm{CI}): 1.17,1.49, \mathrm{P}=1.08 \times 10^{-5}$ ). The association remained significant in the complex model with adjustment of age, sex, BMI, smoking, hypertension, type 2 diabetes, $\mathrm{LDL}$ cholesterol, HDL cholesterol and triglyceride levels $(\mathrm{OR}=1.34,95 \%$ CI: $\left.1.18,1.53, \mathrm{P}=6.97 \times 10^{-6}\right)$. In addition, the associations between $\mathrm{rs} 780094$ and plaque were consistent across the three study centers of the SHS and the three centers of the SHFS (test for heterogeneity: $P_{\text {het }}=0.45$ ) (Figure 2). However, SNP rs780094 was not associated with plaque in the other populations $(\mathrm{OR}=0.99, \mathrm{P}=0.90$ in $\mathrm{EA} ; \mathrm{OR}=1.00, \mathrm{P}=0.99$ in AA).

Since rs1333049 was previously associated with ABI and plaque in $\mathrm{EA}^{24,25}$, we specifically examined these associations in a larger number of multiethnic individuals; however, no 
association was observed with $\mathrm{ABI}$ in any of our populations (beta coefficient $(\beta)=$ $-0.0014, \mathrm{P}=0.37$ in $\mathrm{EA} ; \beta=-0.0013, \mathrm{P}=0.73$ in $\mathrm{AA} ; \beta=0.0026, \mathrm{P}=0.54$ in $\mathrm{AI} ; \beta=$ $-0.0050, \mathrm{P}=0.39$ in MA). In EA and AI, the association between rs1333049 and plaque appeared to be direction-consistent with the original report ${ }^{12}(\mathrm{OR}=1.07, \mathrm{P}=0.02$ in $\mathrm{EA}$; $\mathrm{OR}=1.10, \mathrm{P}=0.05$ in $\mathrm{AI})$, but the results were not statistically significant after Bonferroni correction. In the AA population, rs 1333049 was not associated with plaque $(\mathrm{OR}=0.90, \mathrm{P}=$ $0.08)$.

The exploratory analyses examining potential heterogeneity of gene-phenotype associations by hypertension and by type 2 diabetes status showed that very few SNPs had $P_{\text {het }}<0.05$ between subgroups (Supplemental Tables 2-7). Moreover, none of these heterogeneous associations were observed across all populations.

In the sensitivity analysis, results from the complex model remained unchanged compare to the simple model. In the ARIC study, the association results obtained from models with and without adjusting for PCs did not differ and the causal inference was not changed in EA and AA. In the SHFS, as implemented in SOLAR, the tests for population stratification for rs780094 were not significant $(P>0.05)^{49}$.

\section{Discussion}

In populations of EA, AA, AI and MA ancestry from the PAGE study, we found little evidence for the associations between ten candidate SNPs for clinical CHD and measures of subclinical atherosclerosis, including ABI, common cIMT, and internal cIMT. The GCKR SNP rs780094 was significantly associated with presence of plaque in AI. Each copy of the A allele in rs 780094 was associated with a 1.32-fold increase in odds of carotid plaque (95\% CI: $1.17,1.49, P=1.08 \times 10^{-5}$ ). This finding will need to be replicated in additional samples of AIs and other populations.

These findings are important for several reasons. First, our analysis consisted of a large sample of EA from population-based settings than previous candidate gene studies that examined the association between CHD risk SNPs and subclinical atherosclerosis ${ }^{24-28}$. With our samples, we had $80 \%$ power to detect a $\beta$ of 0.007 or larger in the analysis of ABI, a $\beta$ of 0.008 or larger in the analysis of cIMT, and an OR of 1.12 or larger in the analysis of plaque in the EA population. More importantly, this is the first investigation of these candidate SNPs with subclinical atherosclerosis phenotypes in large and reasonably powered samples of major U.S. populations other than European descendents: AA, AI and MA. In the AA population, we had $80 \%$ power to detect a $\beta$ of 0.016 for ABI, a $\beta$ of 0.019 for cIMT, and an OR of 1.31 for plaque. In the AI population, we had $80 \%$ power to detect a $\beta$ of 0.02 for ABI, a $\beta$ of 0.014 for cIMT, and an OR of 1.19 for plaque. In the MA population, we had $80 \%$ power to detect a $\beta$ of 0.026 in the ABI analysis. Lastly, we were able to assess associations between CHD risk SNPs and carotid plaque, which is a more specific atherosclerosis phenotype and a better predictor of clinical CHD than $\mathrm{cIMT}^{50}$, but has not been frequently examined in previous studies ${ }^{27,28}$. We found no association between CHD risk SNPs and ABI, common and internal cIMTs. SNP rs780094 was highly significantly associated with plaque in AI, but not in EA and AA populations. Though previous studies suggested that the association between 9p21 locus rs1333049 and ABI and plaque may exist $^{24,25}$, we were not able to replicate these associations, likely due to differences in study populations and designs.

Our most significant finding was the association between the A allele in rs780094 and the presence of plaque in $\mathrm{AI}\left(\mathrm{OR}=1.32,95 \% \mathrm{CI}: 1.17,1.49, \mathrm{P}=1.08 \times 10^{-5}\right)$. However, this association was not observed in either the EA or AA populations despite the fact that this 
study had at least $90 \%$ power to detect an OR of 1.32 in our samples. SNP rs780094 is located in an intron of Glucokinase Regulatory Protein gene (GCKR, OMIM: 600842, $2 \mathrm{p} 23.3$ ) and has been associated with fasting glucose, triglycerides, LDL cholesterol, Creactive protein, serum uric acid, serum phospholipid and metabolic traits ${ }^{16,51-56}$. In EA and Asian, rs780094 is in tight LD with $r 1260326\left(r^{2}=0.93\right.$ and 0.90 , respectively), which encodes a common missense variant in GCKR. In AA there is some LD among these SNPs $(\mathrm{r} 2=0.47)$, but the LD in AI is unknown. In both ARIC and CHS, the association between the risk allele (A) of rs780094 and higher levels of fasting serum triacylglycerol, total cholesterol, and serum uric acid but lower levels of fasting blood glucose in EA populations were previously reported ${ }^{57,56,58}$ and consistent with other studies. However, despite these associations, this SNP was not associated with subclinical CHD outcomes in these two studies. In our sample of AI, this association was independent of lipid levels and type 2 diabetes $\left(\mathrm{OR}=1.34,95 \% \mathrm{CI}: 1.18,1.53, \mathrm{P}=6.97 \times 10^{-6}\right)$ after adjusting for sex, age, centers, BMI, smoking, hypertension, type 2 diabetes, LDL cholesterol, HDL cholesterol and triglyceride levels. There have been no previous reports of the association of rs780094 with plaque, but it has been shown to be associated with common cIMT in 455 Caucasians with metabolic syndrome $(\mathrm{P}<0.05)^{59}$. However, we were not able to replicate this association in our samples of EA, which may be due to differences in the study populations since we have population-based individuals, while the previous study focused on a small number of individuals with metabolic syndrome. On the other hand, the association between rs780094 and plaque may be a false positive. However, family studies are robust to population stratification. In our prior evaluation of population stratification in the SHFS using quantitative trait linkage disequilibrium tests ${ }^{49}$, we found no evidence population substructure for this SNP. The A allele is more common in the EA population (40\% in EA vs $20 \%$ in $\mathrm{AI}$ ), whereas the prevalence of plaque was lower (32.9\% in EA vs $45.0 \%$ in $\mathrm{AI}$ ). Similarly, in the AA, the frequency of the A allele in rs780094 is slightly lower (0.18 in AA vs 0.20 in $\mathrm{AI}$ ), whereas the prevalence of plaque is much lower in $\mathrm{AA}$ (31.6\% in $\mathrm{AA}$ vs $45.0 \%$ in $\mathrm{AI}$ ). Given that the A allele is associated with an increased risk of plaque, it does not appear that confounding by EA or AA admixture in the AI population leads to the observed association in AI. In summary, the association between rs780094 and plaque in the AI population needs to be replicated in future studies.

Another suggestive finding is the association between rs1333049 on chromosome 9p21 and prevalence of plaque. SNPs in the chromosome 9p21 region (close to the $C D K N 2 A / 2 B$ gene) have been consistently associated with clinical CHD, incident CHD, heart failure, myocardial infarction, coronary artery calcification, ischemic stroke and abdominal aortic aneurysm in populations of European ancestry ${ }^{12-18}$. However, associations between these SNPs and subclinical atherosclerosis phenotypes have been conflicting ${ }^{22-26}$. While some studies reported associations of rs 1333049 with plaque and $\mathrm{ABI}^{24,25}$, three other candidate studies failed to detect associations between 9p21 SNPs (rs1333049, rs7044859, rs496892, rs7865618, rs 4977574) and cIMT ${ }^{26-28}$. In the current analyses, we observed directionconsistent associations between the $\mathrm{C}$ allele in rs 1333049 and decreased ABI, increased cIMT and increased risk of plaque in our EA population, as in previous findings with clinical CHD and with subclinical atherosclerosis. In a recent meta-analysis of 21 GWAS, rs 10757269, in high LD with rs1333049 $\left(\mathrm{r}^{2}=0.87\right.$ in CEU from HapMap III), was associated with $\mathrm{ABI}\left(\beta=-0.006, \mathrm{P}=2.46 \times 10^{-8}\right)^{21}$. In a previous PAGE analysis ${ }^{60}$ of 6,626 individuals with CHD, rs10757278, in high LD with rs1333049 $\left(\mathrm{r}^{2}=0.9\right.$ in EA) in the 9p21 region, was significantly associated with incident $\mathrm{CHD}$ (hazard ratio $=1.19, \mathrm{P}=4.7 \times$ $\left.10^{-41}\right)^{60}$. The lack of significant associations in our study is likely due to the modest effect size ( $\beta=-0.0014$ in $\mathrm{ABI}$ analyses) and relatively small sample size compared to previous studies. 
There are several aspects of the study that strengthened our findings. First, the current study examined associations between SNPs for clinical CHD and subclinical atherosclerosis intermediate phenotypes, which have been thought to be a way to increase statistical power for finding genes for complex traits ${ }^{61}$. The "upstream" intermediate phenotypes (e.g. plaque), which are more proximal to the genes on the pathogenic pathway, should be more strongly associated with the genetic variants than the "downstream" clinical traits (CHD) ${ }^{62}$. Such association studies may theoretically elucidate how these CHD genetic variants act on the pathogenesis of CHD through the development and progression of atherosclerosis. Second, our analyses included large studies from multiple racial/ethnic backgrounds with well-characterized and harmonized phenotypes. Despite the lack of power to detect the modest associations with ABI, common cIMT and internal cIMT, we have identified a highly significant association in the analyses of plaque.

We also note the limitations of our study. Although phenotypes were carefully harmonized, due to the complexity of these phenotypes and differences in study protocols, some unresolved heterogeneity in the measurement of phenotypes may still exist limiting our power to detect associations. Second, two imputed SNPs with relatively high imputation scores ( $\mathrm{r}^{2}$ is 0.97 for rs 2383207 and 0.91 for rs499818) were used in some of our analyses. However, similar inferences were made when these genotypes were not included in the analyses. Lastly, in the present study, we simply evaluated the published index variant identified from previous GWASs, which were primarily found in populations of European ancestry; therefore, differences in linkage disequilibrium between the available tested SNP and the "causative" variant in different populations were not accounted for in our study and may have obscure true associations in these regions.

In conclusion, using the diverse populations from the PAGE study, we found that rs780094 $(G C K R)$ was significantly associated with the presence of carotid plaque in American Indian populations. This association appears to be population-specific and will need to be replicated in future studies. In addition, there was little evidence that CHD susceptibility variants identified through GWAS influence the development of CHD through subclinical atherosclerosis as assessed by cIMT and ABI.

\section{Supplementary Material}

Refer to Web version on PubMed Central for supplementary material.

\section{Acknowledgments}

(a) The Population Architecture Using Genomics and Epidemiology (PAGE) program is funded by the National Human Genome Research Institute (NHGRI), supported by U01HG004803 (CALiCo), U01HG004798 (EAGLE), U01HG004802 (MEC), U01HG004790 (WHI), and U01HG004801 (Coordinating Center), and their respective NHGRI ARRA supplements. The contents of this paper are solely the responsibility of the authors and do not necessarily represent the official views of the NIH. The complete list of PAGE members can be found at http:// www.pagestudy.org.

(b) The data and materials included in this report result from a collaboration between the following studies:

The "Epidemiologic Architecture for Genes Linked to Environment (EAGLE)" is funded through the NHGRI PAGE program (U01HG004798-01 and its NHGRI ARRA supplement). Genotyping services for select NHANES III SNPs presented here were also provided by the Johns Hopkins University under federal contract number (N01HV-48195) from NHLBI. The study participants derive from the National Health and Nutrition Examination Surveys (NHANES), and these studies are supported by the Centers for Disease Control and Prevention. The findings and conclusions in this report are those of the authors and do not necessarily represent the views of the Centers for Disease Control and Prevention. 
The Multiethnic Cohort study (MEC) characterization of epidemiological architecture is funded through the NHGRI PAGE program (U01HG004802 and its NHGRI ARRA supplement). The MEC study is funded through the National Cancer Institute (R37CA54281, R01 CA63, P01CA33619, U01CA136792, and U01CA98758).

Funding support for the "Epidemiology of putative genetic variants: The Women's Health Initiative" study is provided through the NHGRI PAGE program (U01HG004790 and its NHGRI ARRA supplement). The WHI program is funded by the National Heart, Lung, and Blood Institute; NIH; and U.S. Department of Health and Human Services through contracts N01WH22110, 24152, 32100-2, 32105-6, 32108-9, 32111-13, 32115, 32118-32119, 32122, 42107-26, 42129-32, and 44221. The authors thank the WHI investigators and staff for their dedication, and the study participants for making the program possible. A full listing of WHI investigators can be found at: http://www.whiscience.org/publications/WHI_investigators_shortlist.pdf.

Funding support for the Genetic Epidemiology of Causal Variants Across the Life Course (CALiCo) program was provided through the NHGRI PAGE program (U01HG004803 and its NHGRI ARRA supplement). The following studies contributed to this manuscript and are funded by the following agencies: The Atherosclerosis Risk in Communities (ARIC) Study is carried out as a collaborative study supported by National Heart, Lung, and Blood Institute contracts N01-HC-55015, N01-HC-55016, N01-HC-55018, N01-HC-55019, N01-HC-55020, N01HC-55021, N01-HC-55022. The Coronary Artery Risk Development in Young Adults (CARDIA) study is supported by the following National Institutes of Health, National Heart, Lung and Blood Institute contracts: N01HC-95095; N01-HC-48047; N01-HC-48048; N01-HC-48049; N01-HC-48050; N01-HC-45134; N01-HC-05187; and N01-HC-45205. The Cardiovascular Health Study (CHS) is supported by contracts HHSN268201200036C, N01-HC-85239, N01-HC-85079 through N01-HC-85086, N01-HC-35129, N01 HC-15103, N01 HC-55222, N01HC-75150, N01-HC-45133, and grant HL080295 from the National Heart, Lung, and Blood Institute (NHLBI), with additional contribution from the National Institute of Neurological Disorders and Stroke (NINDS). Additional support was provided through AG-023629, AG-15928, AG-20098, and AG-027058 from the National Institute on Aging (NIA). The Strong Heart Study (SHS) is supported by NHLBI grants U01 HL65520, U01 HL41642, U01 HL41652, U01 HL41654, and U01 HL65521. The opinions expressed in this paper are those of the author(s) and do not necessarily reflect the views of the Indian Health Service.

Assistance with phenotype harmonization, SNP selection and annotation, data cleaning, data management, integration and dissemination, and general study coordination was provided by the PAGE Coordinating Center (U01HG004801-01 and its NHGRI ARRA supplement). The National Institutes of Mental Health also contributes to the support for the Coordinating Center. The PAGE consortium thanks the staff and participants of all PAGE studies for their important contributions.

\section{References}

1. Lloyd-Jones D, Adams RJ, Brown TM, et al. Executive summary: heart disease and stroke statistics -2010 update: a report from the American Heart Association. Circulation. 2010; 121:948-954. [PubMed: 20177011]

2. Lorenz MW, Markus HS, Bots ML, et al. Prediction of clinical cardiovascular events with carotid intima-media thickness: a systematic review and meta-analysis. Circulation. 2007; 115:459-467. [PubMed: 17242284]

3. Chambless LE, Folsom AR, Clegg LX, et al. Carotid wall thickness is predictive of incident clinical stroke: the Atherosclerosis Risk in Communities (ARIC) study. Am J Epidemiol. 2000; 151:478487. [PubMed: 10707916]

4. Burke GL, Evans GW, Riley WA, et al. Arterial wall thickness is associated with prevalent cardiovascular disease in middle-aged adults. The Atherosclerosis Risk in Communities (ARIC) Study. Stroke. 1995; 26:386-391. [PubMed: 7886711]

5. Manolio TA, Burke GL, O'Leary DH, et al. Relationships of cerebral MRI findings to ultrasonographic carotid atherosclerosis in older adults: the Cardiovascular Health Study. CHS Collaborative Research Group. Arterioscler Thromb Vasc Biol. 1999; 19:356-365. [PubMed: 9974419]

6. Jain A, McClelland RL, Polak JF, et al. Cardiovascular imaging for assessing cardiovascular risk in asymptomatic men versus women: the multi-ethnic study of atherosclerosis (MESA). Circ Cardiovasc Imaging. 2011; 4:8-15. [PubMed: 21068189]

7. Stein JH, Korcarz CE, Hurst RT, et al. Use of carotid ultrasound to identify subclinical vascular disease and evaluate cardiovascular disease risk: a consensus statement from the American Society of Echocardiography Carotid Intima-Media Thickness Task Force. Endorsed by the Society for Vascular Medicine. J Am Soc Echocardiogr. 2008; 21:93-111. quiz 189-190. [PubMed: 18261694] 
8. Roman MJ, Kizer JR, Best LG, et al. Vascular biomarkers in the prediction of clinical cardiovascular disease: the Strong Heart Study. Hypertension. 2012; 59:29-35. [PubMed: 22068872]

9. Zheng ZJ, Sharrett AR, Chambless LE, et al. Associations of ankle-brachial index with clinical coronary heart disease, stroke and preclinical carotid and popliteal atherosclerosis: the Atherosclerosis Risk in Communities (ARIC) Study. Atherosclerosis. 1997; 131:115-125. [PubMed: 9180252]

10. O'Hare AM, Katz R, Shlipak MG, et al. Mortality and cardiovascular risk across the ankle-arm index spectrum: results from the Cardiovascular Health Study. Circulation. 2006; 113:388-393. [PubMed: 16432070]

11. Resnick HE, Lindsay RS, McDermott MM, et al. Relationship of high and low ankle brachial index to all-cause and cardiovascular disease mortality: the Strong Heart Study. Circulation. 2004; 109:733-739. [PubMed: 14970108]

12. Genome-wide association study of 14,000 cases of seven common diseases and 3,000 shared controls. Nature. 2007; 447:661-678. [PubMed: 17554300]

13. Helgadottir A, Thorleifsson G, Manolescu A, et al. A common variant on chromosome 9p21 affects the risk of myocardial infarction. Science. 2007; 316:1491-1493. [PubMed: 17478679]

14. Samani NJ, Erdmann J, Hall AS, et al. Genomewide association analysis of coronary artery disease. N Engl J Med. 2007; 357:443-453. [PubMed: 17634449]

15. Schunkert H, Konig IR, Kathiresan S, et al. Large-scale association analysis identifies 13 new susceptibility loci for coronary artery disease. Nat Genet. 2011; 43:333-338. [PubMed: 21378990]

16. Willer CJ, Sanna S, Jackson AU, et al. Newly identified loci that influence lipid concentrations and risk of coronary artery disease. Nat Genet. 2008; 40:161-169. [PubMed: 18193043]

17. McPherson R, Pertsemlidis A, Kavaslar N, et al. A common allele on chromosome 9 associated with coronary heart disease. Science. 2007; 316:1488-1491. [PubMed: 17478681]

18. Larson MG, Atwood LD, Benjamin EJ, et al. Framingham Heart Study 100K project: genomewide associations for cardiovascular disease outcomes. BMC Med Genet. 2007; 8(Suppl 1):S5. [PubMed: 17903304]

19. O’Donnell CJ, Cupples LA, D'Agostino RB, et al. Genome-wide association study for subclinical atherosclerosis in major arterial territories in the NHLBI's Framingham Heart Study. BMC medical genetics. 2007; 8(Suppl 1):S4. [PubMed: 17903303]

20. Bis JC, Kavousi M, Franceschini N, et al. Meta-analysis of genome-wide association studies from the CHARGE consortium identifies common variants associated with carotid intima media thickness and plaque. Nature genetics. 2011; 43:940-947. [PubMed: 21909108]

21. Murabito JM, White CC, Kavousi M, et al. Association between chromosome 9p21 variants and the ankle-brachial index identified by a meta-analysis of 21 genome-wide association studies. Circ Cardiovasc Genet. 2012; 5:100-112. [PubMed: 22199011]

22. Wild PS, Zeller T, Schillert A, et al. A Genome-wide Association Study Identifies LIPA as a Susceptibility Gene for Coronary Artery Disease. Circ Cardiovasc Genet. 2011

23. Shrestha S, Irvin MR, Taylor KD, et al. A genome-wide association study of carotid atherosclerosis in HIV-infected men. AIDS. 2010; 24:583-592. [PubMed: 20009918]

24. Ye S, Willeit J, Kronenberg F, et al. Association of genetic variation on chromosome 9p21 with susceptibility and progression of atherosclerosis: a population-based, prospective study. $\mathrm{J}$ Am Coll Cardiol. 2008; 52:378-384. [PubMed: 18652946]

25. Cluett C, McDermott MM, Guralnik J, et al. The 9p21 myocardial infarction risk allele increases risk of peripheral artery disease in older people. Circulation Cardiovascular genetics. 2009; 2:347353. [PubMed: 20031606]

26. Samani NJ, Raitakari OT, Sipila K, et al. Coronary artery disease-associated locus on chromosome 9p21 and early markers of atherosclerosis. Arterioscler Thromb Vasc Biol. 2008; 28:1679-1683. [PubMed: 18599798]

27. Cunnington MS, Mayosi BM, Hall DH, et al. Novel genetic variants linked to coronary artery disease by genome-wide association are not associated with carotid artery intima-media thickness or intermediate risk phenotypes. Atherosclerosis. 2009; 203:41-44. [PubMed: 18675980] 
28. Conde L, Bevan S, Sitzer M, et al. Novel associations for coronary artery disease derived from genome wide association studies are not associated with increased carotid intima-media thickness, suggesting they do not act via early atherosclerosis or vessel remodeling. Atherosclerosis. 2011

29. Matise TC, Ambite JL, Buyske S, et al. The Next PAGE in Understanding Complex Traits: Design for the Analysis of Population Architecture Using Genetics and Epidemiology (PAGE) Study. Am J Epidemiol. 2011; 174:849-859. [PubMed: 21836165]

30. The ARIC investigators. The Atherosclerosis Risk in Communities (ARIC) Study: design and objectives. Am J Epidemiol. 1989; 129:687-702. [PubMed: 2646917]

31. Fried LP, Borhani NO, Enright P, et al. The Cardiovascular Health Study: design and rationale. Ann Epidemiol. 1991; 1:263-276. [PubMed: 1669507]

32. Lee ET, Welty TK, Fabsitz R, et al. The Strong Heart Study. A study of cardiovascular disease in American Indians: design and methods. Am J Epidemiol. 1990; 132:1141-1155. [PubMed: 2260546]

33. North KE, Howard BV, Welty TK, et al. Genetic and environmental contributions to cardiovascular disease risk in American Indians: the strong heart family study. Am J Epidemiol. 2003; 157:303-314. [PubMed: 12578801]

34. Gunter, ELB. KS, Laboratory procedures used for the third National Health and Nutrition Examination Survey (NHANES III), 1988-1994. Atlanta, GA and Hyattsville, MD: National Center for Environmental Health and National Center for Health Statistics, Centers for Disease Control and Prevention; 1996. http://wwwcdcgov/nchs/data/nhanes/nhanes3/cdrom/nchs/manuals/ labmanpdf

35. Psaty BM, O'Donnell CJ, Gudnason V, et al. Cohorts for Heart and Aging Research in Genomic Epidemiology (CHARGE) Consortium: Design of prospective meta-analyses of genome-wide association studies from 5 cohorts. Circ Cardiovasc Genet. 2009; 2:73-80. [PubMed: 20031568]

36. Howard G, Sharrett AR, Heiss G, et al. Carotid artery intimal-medial thickness distribution in general populations as evaluated by B-mode ultrasound. ARIC Investigators. Stroke. 1993; 24:1297-1304. [PubMed: 8362421]

37. O'Leary DH, Polak JF, Wolfson SK Jr, et al. Use of sonography to evaluate carotid atherosclerosis in the elderly. The Cardiovascular Health Study. CHS Collaborative Research Group. Stroke. 1991; 22:1155-1163. [PubMed: 1926258]

38. O'Leary DH, Polak JF, Kronmal RA, et al. Distribution and correlates of sonographically detected carotid artery disease in the Cardiovascular Health Study. The CHS Collaborative Research Group. Stroke. 1992; 23:1752-1760. [PubMed: 1448826]

39. The ARIC Study Group. High-resolution B-mode ultrasound reading methods in the Atherosclerosis Risk in Communities (ARIC) cohort. J Neuroimaging. 1991; 1:168-172. [PubMed: 10149810]

40. Roman MJ, Saba PS, Pini R, et al. Parallel cardiac and vascular adaptation in hypertension. Circulation. 1992; 86:1909-1918. [PubMed: 1451262]

41. AbuRahma AF, Wulu JT Jr, Crotty B. Carotid plaque ultrasonic heterogeneity and severity of stenosis. Stroke. 2002; 33:1772-1775. [PubMed: 12105350]

42. Boerwinkle E, Chakraborty R, Sing CF. The use of measured genotype information in the analysis of quantitative phenotypes in man. I. Models and analytical methods. Ann Hum Genet. 1986; 50:181-194. [PubMed: 3435047]

43. Higgins JP, Thompson SG, Deeks JJ, et al. Measuring inconsistency in meta-analyses. BMJ. 2003; 327:557-560. [PubMed: 12958120]

44. Kottgen A, Glazer NL, Dehghan A, et al. Multiple loci associated with indices of renal function and chronic kidney disease. Nat Genet. 2009; 41:712-717. [PubMed: 19430482]

45. Havill LM, Dyer TD, Richardson DK, et al. The quantitative trait linkage disequilibrium test: a more powerful alternative to the quantitative transmission disequilibrium test for use in the absence of population stratification. BMC Genet. 2005; 6(Suppl 1):S91. [PubMed: 16451707]

46. Almasy L, Blangero J. Multipoint quantitative-trait linkage analysis in general pedigrees. Am J Hum Genet. 1998; 62:1198-1211. [PubMed: 9545414]

47. Blangero J, Almasy L. Multipoint oligogenic linkage analysis of quantitative traits. Genet Epidemiol. 1997; 14:959-964. [PubMed: 9433607] 
48. Burton PR, Hansell AL, Fortier I, et al. Size matters: just how big is BIG?: Quantifying realistic sample size requirements for human genome epidemiology. Int J Epidemiol. 2009; 38:263-273. [PubMed: 18676414]

49. North KE, Goring HH, Cole SA, et al. Linkage analysis of LDL cholesterol in American Indian populations: the Strong Heart Family Study. J Lipid Res. 2006; 47:59-66. [PubMed: 16264198]

50. Johnsen SH, Mathiesen EB. Carotid plaque compared with intima-media thickness as a predictor of coronary and cerebrovascular disease. Curr Cardiol Rep. 2009; 11:21-27. [PubMed: 19091171]

51. Wallace C, Newhouse SJ, Braund P, et al. Genome-wide association study identifies genes for biomarkers of cardiovascular disease: serum urate and dyslipidemia. Am J Hum Genet. 2008; 82:139-149. [PubMed: 18179892]

52. Kathiresan S, Melander O, Guiducci C, et al. Six new loci associated with blood low-density lipoprotein cholesterol, high-density lipoprotein cholesterol or triglycerides in humans. Nat Genet. 2008; 40:189-197. [PubMed: 18193044]

53. Ridker PM, Pare G, Parker A, et al. Loci related to metabolic-syndrome pathways including LEPR, HNF1A, IL6R, and GCKR associate with plasma C-reactive protein: the Women's Genome Health Study. Am J Hum Genet. 2008; 82:1185-1192. [PubMed: 18439548]

54. Kolz M, Johnson T, Sanna S, et al. Meta-analysis of 28,141 individuals identifies common variants within five new loci that influence uric acid concentrations. PLoS Genet. 2009; 5:e1000504. [PubMed: 19503597]

55. Dupuis J, Langenberg C, Prokopenko I, et al. New genetic loci implicated in fasting glucose homeostasis and their impact on type 2 diabetes risk. Nat Genet. 2010; 42:105-116. [PubMed: 20081858]

56. Dumitrescu L, Carty CL, Taylor K, et al. Genetic determinants of lipid traits in diverse populations from the population architecture using genomics and epidemiology (PAGE) study. PLoS Genet. 2011; 7:e1002138. [PubMed: 21738485]

57. Bi M, Kao WH, Boerwinkle E, et al. Association of rs780094 in GCKR with metabolic traits and incident diabetes and cardiovascular disease: the ARIC Study. PLoS One. 2010; 5:e11690. [PubMed: 20661421]

58. Kozian DH, Barthel A, Cousin E, et al. Glucokinase-activating GCKR polymorphisms increase plasma levels of triglycerides and free fatty acids, but do not elevate cardiovascular risk in the Ludwigshafen Risk and Cardiovascular Health Study. Horm Metab Res. 2010; 42:502-506. [PubMed: 20352598]

59. Mohas M, Kisfali P, Jaromi L, et al. GCKR gene functional variants in type 2 diabetes and metabolic syndrome: do the rare variants associate with increased carotid intima-media thickness? Cardiovasc Diabetol. 2010; 9:79. [PubMed: 21114848]

60. Franceschini N, Carty C, Buzkova P, et al. Association of genetic variants and incident coronary heart disease in multi-ethnic cohorts. The PAGE Study, Circulation. Cardiovascular genetics. 2011

61. Plomin R, Haworth CM, Davis OS. Common disorders are quantitative traits. Nat Rev Genet. 2009; 10:872-878. [PubMed: 19859063]

62. Pan WH, Lynn KS, Chen CH, et al. Using endophenotypes for pathway clusters to map complex disease genes. Genet Epidemiol. 2006; 30:143-154. [PubMed: 16437587] 


\section{Highlights}

- We examine the associations between CAD risk SNPs and subclinical atherosclerosis

- We include large samples of African Americans, Mexican Americans, and American Indians

- SNP rs780094 is significantly associated with plaque in American Indians

- Lack of association between CAD risk SNPs with ABI and cIMT 


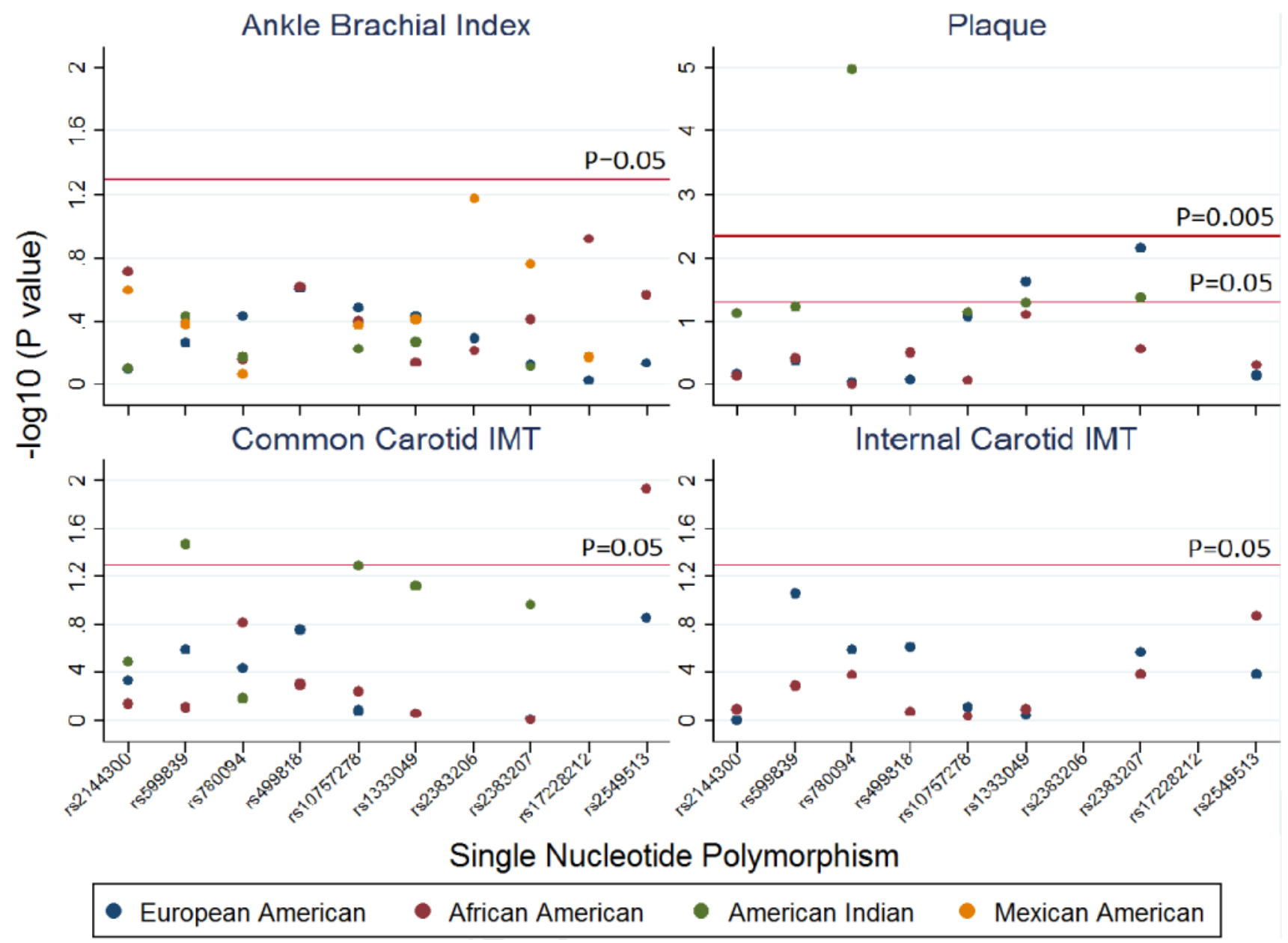

Figure 1.

Associations of Single Nucleotide Polymorphisms with Ankle Brachial Index, Plaque,

Common Carotid and Internal Carotid Artery Intima-media Thickness (IMT) in the

Population Architecture Using Genetics and Epidemiology (PAGE) study, by Populations. 


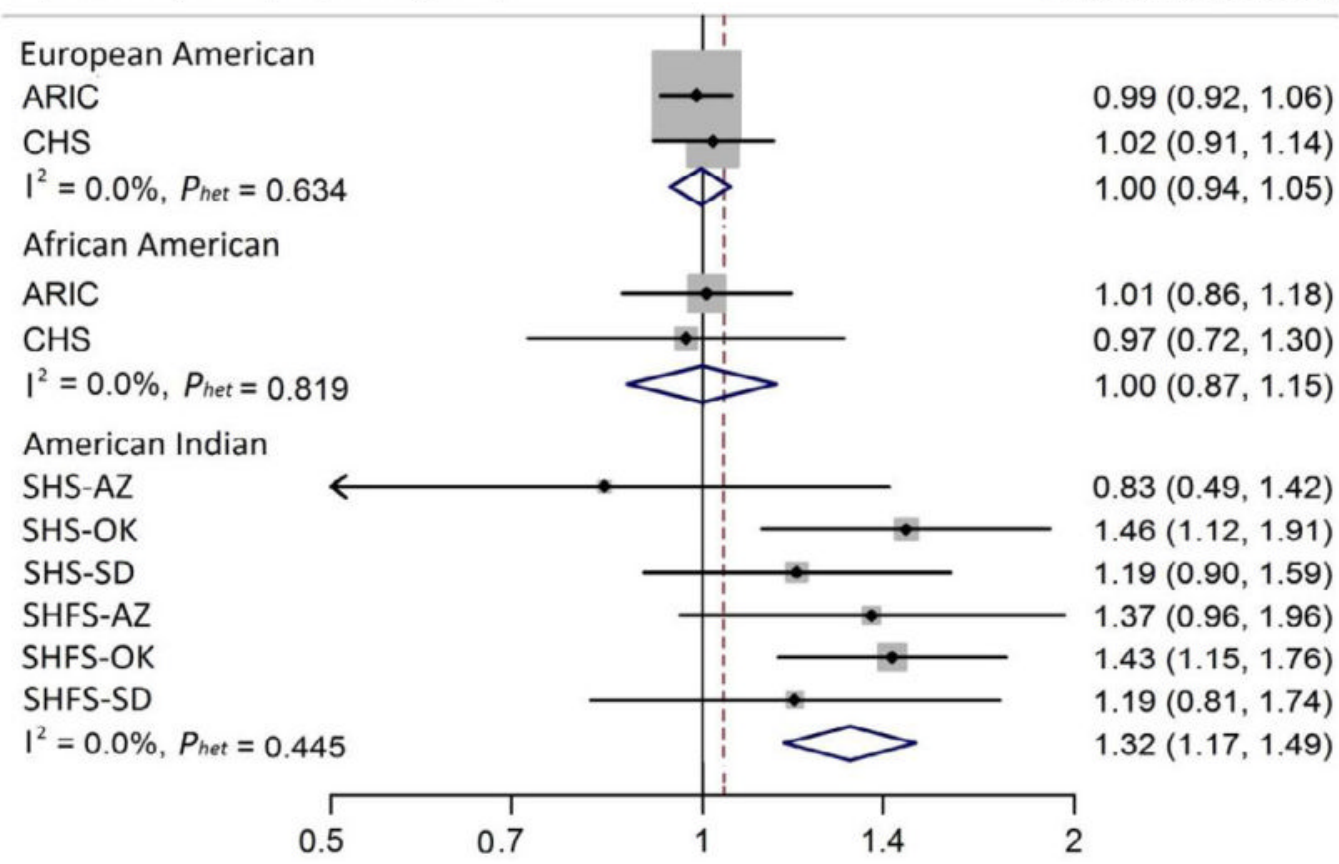

Figure 2.

Population- and study-specific and pooled associations between rs780094 and plaque in the Population Architecture Using Genetics and Epidemiology (PAGE) study, by populations. Odd ratio and $95 \%$ confidence intervals $(95 \% \mathrm{CI})$ are obtained from logistic regression model adjusting for sex, age and center if applicable. $\mathrm{I}^{2}$ and $P_{h e t}$ are obtained from Cochran's Q test using a fixed effect model. The size of each square is proportional to the percent weight that each population-, study-specific group contributed in the overall association. Diamond represents the pooled odds ratio for each population. Bars represent the $95 \%$ confidence intervals for the odds ratios.

Abbreviations: ARIC, Atherosclerosis Risk in Communities; AZ, Arizona; CHS, Cardiovascular Health Study; NHANES, National Health and Nutrition Examination Survey; OK, Oklahoma; SD, South Dakota; SHFS, Strong Heart Family Study; SHS, Strong Heart Study. 
Table 1

Characteristics of Participants in the Analysis of Ankle Brachial Index and Intima-media thickness/Plaque in the Population Architecture Using Genetics and Epidemiology (PAGE) study, by Populations

\begin{tabular}{|c|c|c|c|c|}
\hline & $\begin{array}{l}\text { European Americans } \\
\text { (EA) }\end{array}$ & $\begin{array}{l}\text { African Americans } \\
\text { (AA) }\end{array}$ & $\begin{array}{l}\text { American Indians } \\
\text { (AI) }\end{array}$ & $\begin{array}{c}\text { Mexican Americans } \\
\text { (MA) }\end{array}$ \\
\hline $\begin{array}{l}\text { Participant characteristics-Ankle Brachial } \\
\text { Index analysis* }\end{array}$ & $\mathrm{N}=\mathbf{1 5}, \mathbf{1 1 3}$ & $\mathrm{N}=\mathbf{4 , 4 7 2}$ & $N=1,984$ & $N=944$ \\
\hline Ankle brachial index, mg/dL & $1.11(0.14)$ & $1.09(0.14)$ & $1.12(0.14)$ & $1.11(0.13)$ \\
\hline Age, years & $60.5(6.3)$ & $57.3(6.2)$ & $63.3(7.8)$ & $57.2(11.9)$ \\
\hline Female, $\%$ & 53.6 & 60.4 & 64.4 & 48.3 \\
\hline Body-mass index, $\mathrm{kg} / \mathrm{m}^{2}$ & $27.0(4.8)$ & $29.4(5.9)$ & $31.2(6.6)$ & $29.0(5.3)$ \\
\hline \multicolumn{5}{|l|}{ Smoking status, $\%$} \\
\hline Current & 20.3 & 26.8 & 29.1 & 20.0 \\
\hline Former & 38.1 & 26.4 & 34.5 & 33.1 \\
\hline Never & 41.6 & 46.8 & 36.3 & 46.9 \\
\hline Type 2 diabetes, $\%$ & 10.1 & 20.0 & 47.1 & 15.5 \\
\hline Hypertension, \% & 39.8 & 60.5 & 54.4 & 41.6 \\
\hline LDL Cholesterol, mg/dL & $132.1(37.2)$ & $134.2(41.5)$ & $118.0(32.8)$ & $126.8(32.6)$ \\
\hline HDL Cholesterol, mg/dL & $51.3(16.4)$ & $55.5(17.4)$ & $42.1(13.4)$ & $48.5(13.8)$ \\
\hline Triglycerides, mg/dL & $144.8(96.2)$ & $114.8(76.7)$ & $154.8(112.7)$ & $186.9(148.7)$ \\
\hline $\begin{array}{l}\text { Participant characteristics-Intima-media } \\
\text { thickness/plaque analysis\# }\end{array}$ & $\mathrm{N}=\mathbf{1 3 , 3 3 7}$ & $\mathbf{N}=\mathbf{3 , 8 0 9}$ & $N=5,353$ & NA \\
\hline Common Carotid IMT, mm & $0.77(0.16)$ & $0.78(0.16)$ & $0.70(0.16)$ & NA \\
\hline Internal Carotid IMT, mm & $0.93(0.32)$ & $0.83(0.23)$ & NA & NA \\
\hline Prevalence of Plaque, $\%$ & 32.9 & 31.6 & 45.0 & NA \\
\hline Age, years & $60.2(5.3)$ & $57.5(5.8)$ & $50.8(13.9)$ & NA \\
\hline Female, $\%$ & 54.2 & 62.6 & 62.0 & NA \\
\hline Body-mass Index, $\mathrm{kg} / \mathrm{m}^{2}$ & $26.9(4.8)$ & $29.3(5.9)$ & $32.0(7.4)$ & NA \\
\hline Smoking status, \% & & & & NA \\
\hline Current & 20.2 & 26.0 & 32.4 & NA \\
\hline Former & 38.4 & 26.8 & 29.7 & NA \\
\hline Never & 41.5 & 47.2 & 37.9 & NA \\
\hline Type 2 diabetes, $\%$ & 10.6 & 20.8 & 34.0 & NA \\
\hline Hypertension, \% & 37.9 & 60.3 & 43.0 & NA \\
\hline LDL Cholesterol, mg/dL & $132.6(37.2)$ & $135.0(42.4)$ & $106.5(30.5)$ & NA \\
\hline HDL Cholesterol, mg/dL & $51.6(16.4)$ & $55.6(17.4)$ & $47.6(14.3)$ & NA \\
\hline Triglycerides, mg/dL & $141.0(91.9)$ & $113.9(74.5)$ & $161.3(112.6)$ & NA \\
\hline
\end{tabular}

Abbreviations: N/A, not applicable.

a Data are mean (standard deviation).

${ }^{b}$ Ankle Brachial Index was measured in participants of the ARIC study, CHS, NHANES 1999-2002, and SHS. Participants were excluded if they did not self identify as any of above populations, or did not consent to genetic study, or missed Ankle Brachial Index measurement or ABI > 1.4. SNP rs17228212 and rs2383206 were not genotyped in the CHS and SHS cohort component, so sample sizes for the analysis of these two SNPs were 11,522 in EA, 3,714 in AA and 944 in MA. SNP rs2549513 and rs499818 were not genotyped in the NHANES 1999-2002 and SHS cohort component, so sample sizes for the analysis of these two SNPs were 12,739 in EA and 3,776 in AA. 
${ }^{c}$ Intima-media thickness and plaque were measured in participants of the ARIC study, CHS, SHS and SHFS. Participants were excluded if they did not self identify as any of above populations, or did not consent to genetic study, or not measured for carotid sonogram. SNP rs2549513 and rs499818 were not genotyped in the SHS, so sample sizes for the analysis of these two SNPs associated with IMT/plaque were 13,337 in EA and 3,809 in AA. 


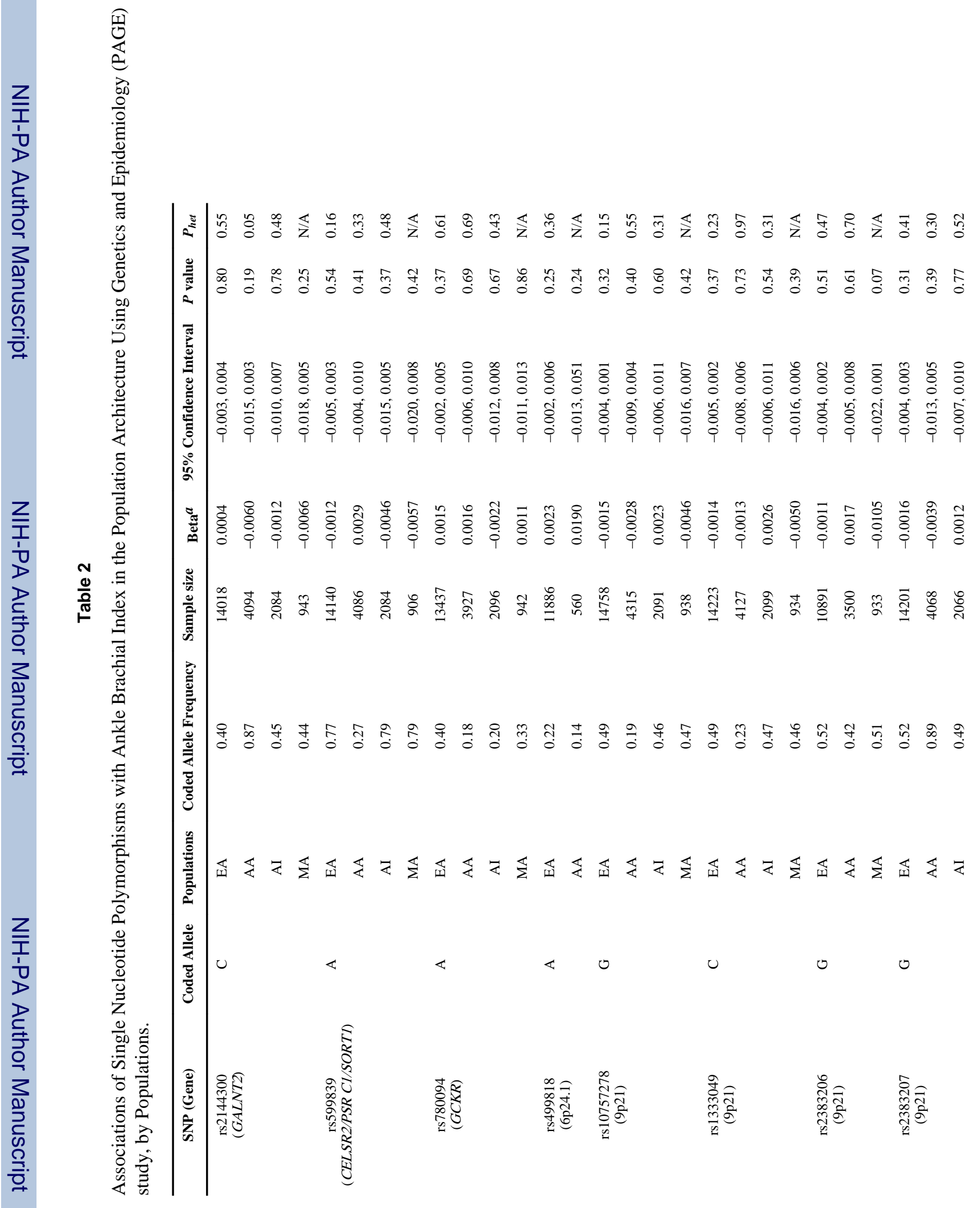




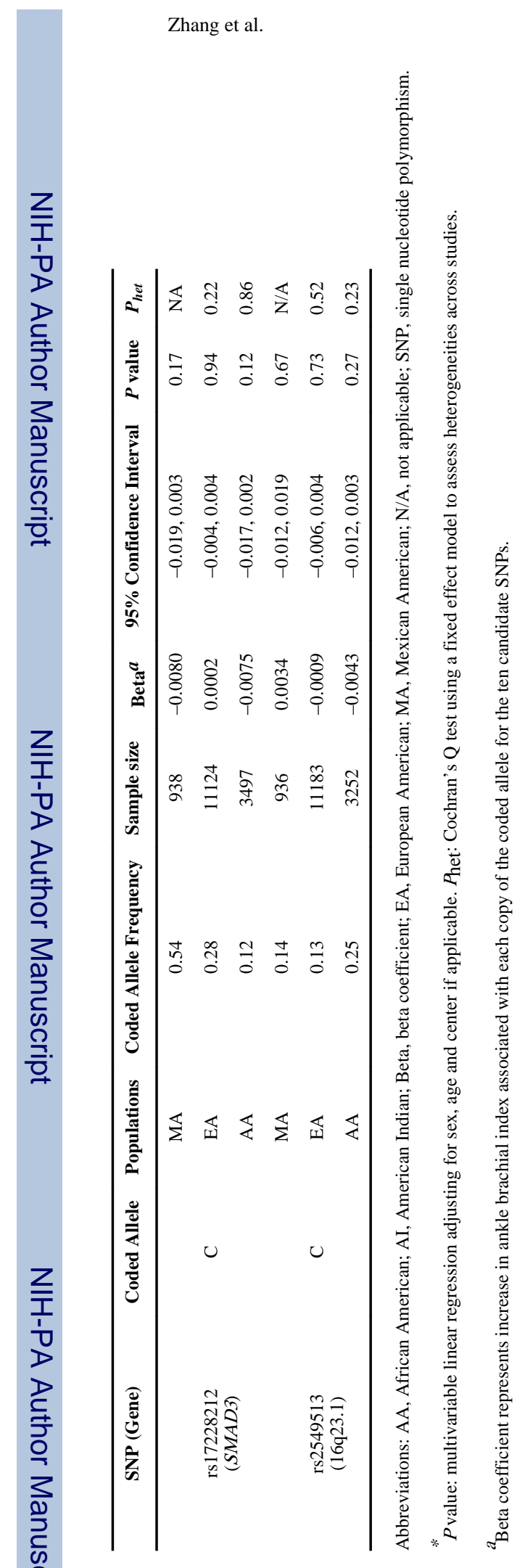

Atherosclerosis. Author manuscript; available in PMC 2014 June 01. 


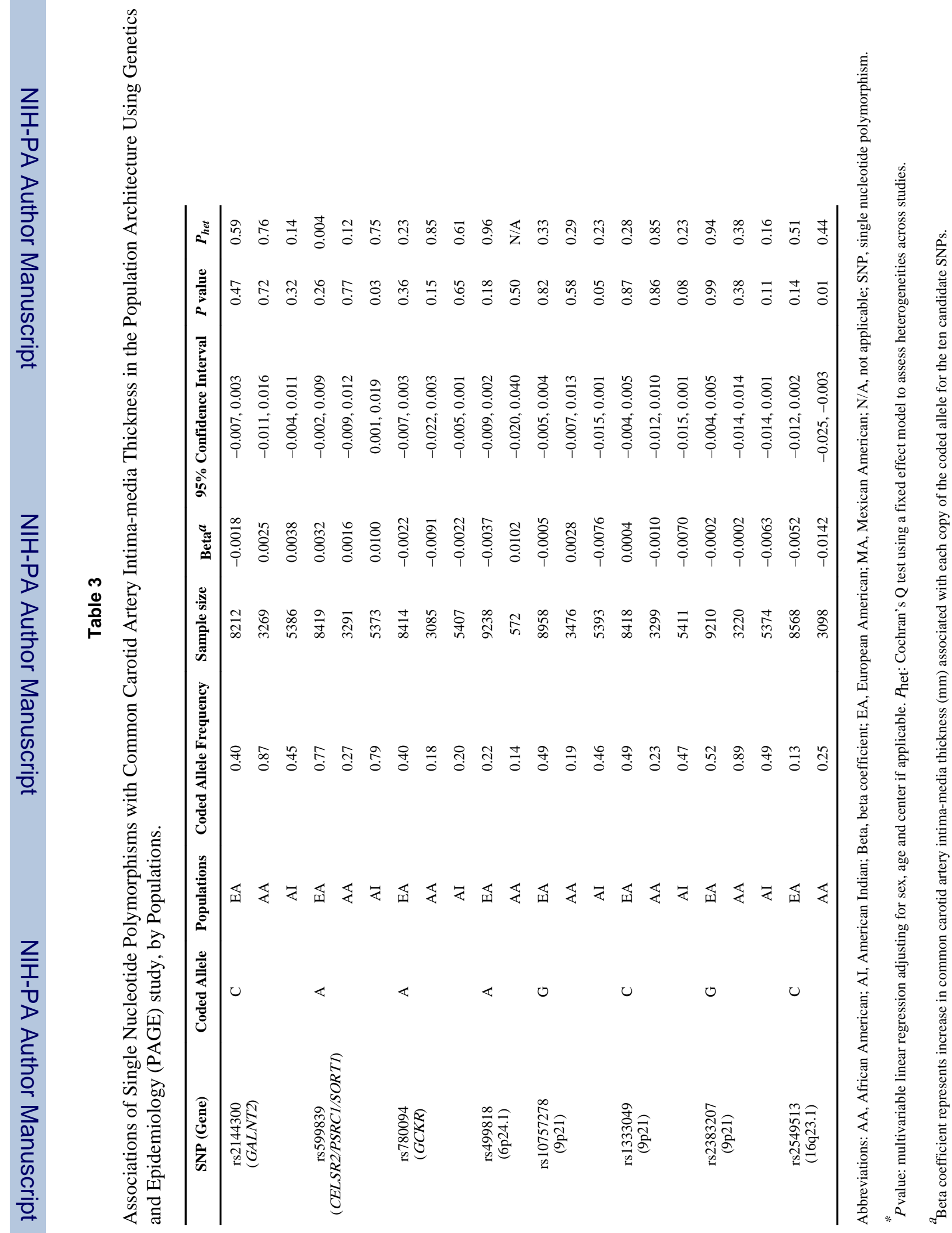




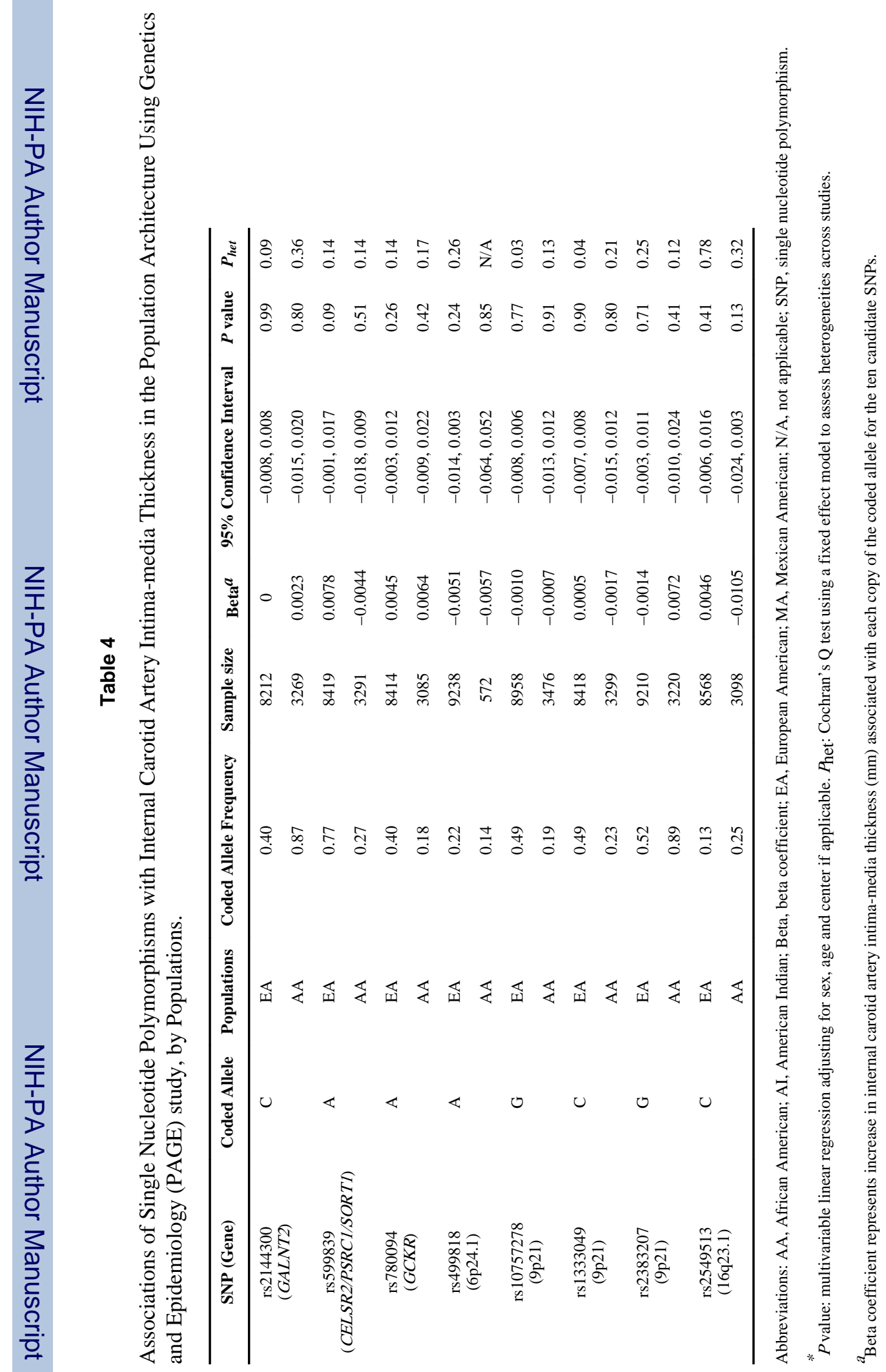




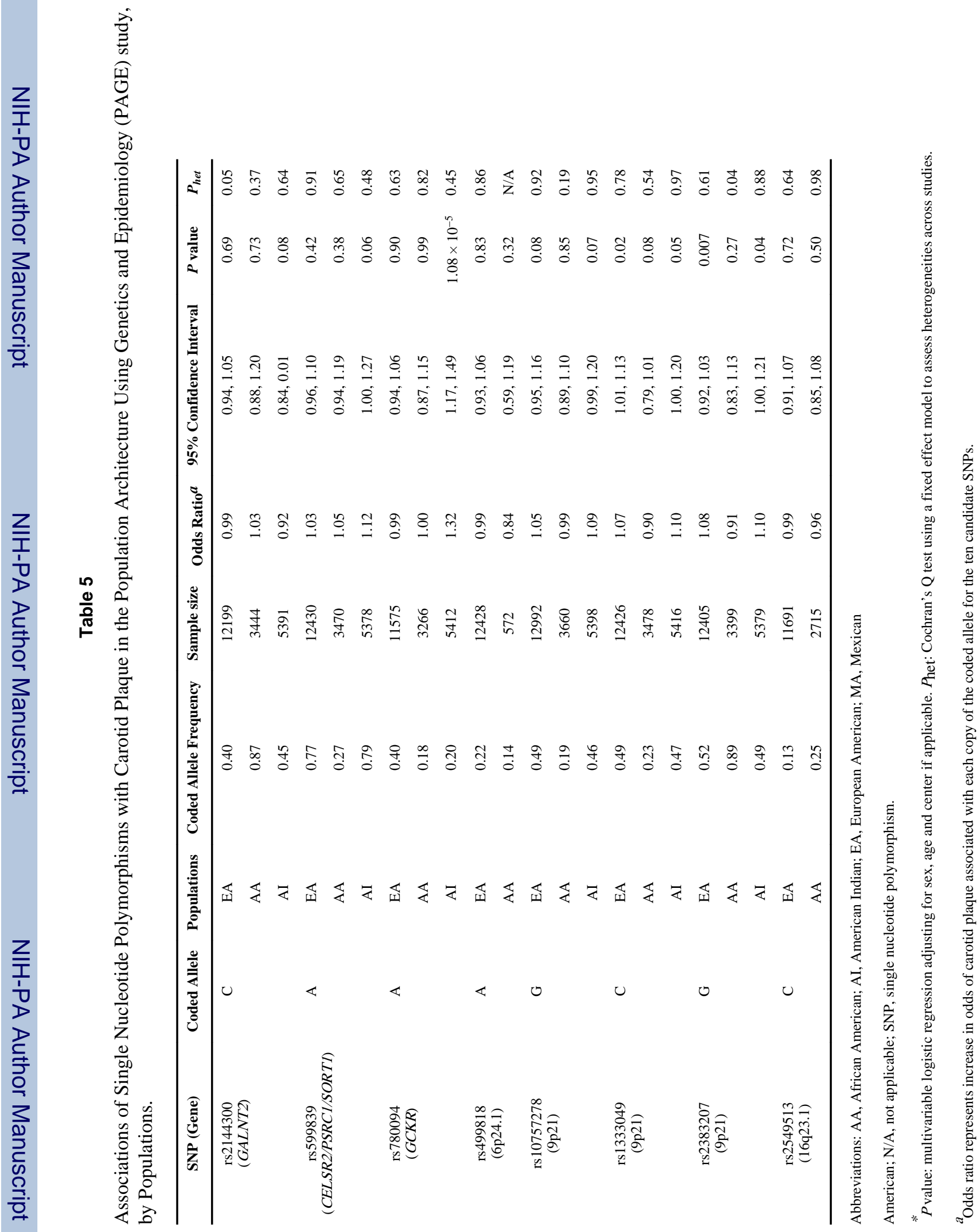

